Brief Report: Identifying Defenders of Peer Victimization

Diana J. Meter ${ }^{\mathrm{a}}$

Noel A. Card ${ }^{b}$

${ }^{a}$ School of Behavioral and Brain Sciences, The University of Texas at Dallas, Richardson, Texas

${ }^{b}$ Neag School of Education, University of Connecticut, Storrs, Connecticut

${ }^{a}$ Corresponding author: Diana J. Meter, diana.meter@utdallas.edu, 800 W. Campbell Rd., The University of Texas at Dallas, Richardson, TX 75080-3021 


\begin{abstract}
Betweenness centrality quantifies the amount of network flow that a network member controlsas hypothetical traffic passes between network members. Those with high betweenness centrality within the peer social network based on nominations of liking may be especially important connectors between individuals who do not like each other. This study tested the hypothesis that individuals' betweenness centrality would predict their defending of victimized peers. After controlling for popularity, perception of being liked, and defenders' victimization, betweenness centrality predicted defending. Those found to be connectors within the peer group were more likely to be those who defend peer victims. This investigation showed that analysis of betweenness centrality is a viable way to identify potential defenders in research and also those who could potentially act as mediators.

Keywords: Betweenness centrality, defending, peer victimization
\end{abstract}




\section{Brief Report: Identifying Defenders of Peer Victimization}

Parents, educators, researchers, and youth themselves are concerned about peer victimization during early adolescence due to its association with adjustment problems (Card, Isaacs, \& Hodges, 2007). Although a decrease in self-reported victimization has been observed as youth transition to middle school, youth must navigate a new social world in middle school, which can begin with an increase in aggression toward peers as youth assert dominance in the new social hierarchy (Pellegrini \& Long, 2002). Peer victimization is the receipt of overt or relational aggression from others (Card, Stucky, Sawalani, \& Little, 2008). Ittypically occurs in the presence of peers(Hawkins, Pepler, \& Craig, 2001). Some youth act as passive bystanders anddo nothing when peers are victimized, while others, referred to as defenders, enact behavior aimed at stopping peer victimization (Salmivalli, 2010).

Research on defenders is limited, but a recent effort has been made to discover factors associated with defending during episodes of peer victimization. Early adolescence is an ideal time in which to study defending due to the tendency for individual and contextual norms to predict early adolescents' behavior in regard to bullying. For example, Salmivalli and Voeten (2004) found a decrease in antibullying attitudes and norms as participants reached early adolescence; these norms predicted behavior.Individual, interpersonal, and contextual variables that predict defending have been studied. Empathy, efficacy, and theory of mind-related variables are associated with defending (e.g. Pöyhönen, Juvonen, \&Salmivalli, 2010; Barchia\&Bussey, 201; Gini, Albiero, Benelli, \&Altoè, 2008). Youth who are able to understand others' cognitive mental states may feel a heightened need to intervene on behalf of their peers. Efficacy to defend is associated with defending (Pronk, Goossens Olthof, De Mey, \&Willemen, 2013). Defenders tend to be accepted, have high status, and be perceived as popular (Caravita, Di 
Blasio, \&Salmivalli, 2010; Pöyhönen et al., 2010; Sainio et al., 2010; Salmivalli, Lagerspetz, Björkqvist, Österman, \&Kaukialnen, 1996). A young person's relationship with a victim predicts whether they will intervene on behalf of that peer (Pronk et al., 2013; Tisak\&Tisak, 1996).

Recently, network variables been considered to explain defending of peer victims(Huitsing, \&Veenstra, 2012).Among children, there was a tendency for youth who share a bully to like each other, and youth who are rejected by the same peers tend to like each other (Huitsing, van Duijn, Snijders, Wang, Sainio, Salmivalli, \&Veenstra, 2010). Child and adolescent victims who shared bullies were found to defend each other over time, but defenders were at risk for victimization by if they defended the individual that the bully bullies (Huitsing, Snijders, Van Duijn, \&Veenstra, 2014). There may be a unique position in which individuals can defend peers effectively due to being links between youth who do not like each other. This study investigated whether betweenness centrality predicteddefending of victimized peers.

Within a peer social network, betweenness centrality is the "traffic flow" between different individuals (Borgatti, 2005). Individuals in a network are connected by paths representing a relation, such as liking a peer. Betweenness centrality is theamount of times that an individual needs to be connected to another individual (our individual of interest), in order to reach another individual via the shortest path (Borgatti, 2005). Betweenness centrality is therefore a measure of how well specific individuals serve as intermediaries between other individuals in the same network (Neal, 2008). Higher betweenness centrality is representative of how often node $k$ (Katie) creates a path from $I$ (Ira)to $j$ (Jane), with the assumption that Ira and Jane do not like each other, or would not have an intermediary (Katie) on the shortest path between them; however, they both like Katie, who connects them. 
If one can imagine an episode of peer victimization, although there are likely many bystanders present, those with high betweenness centrality may be better positionedto defend a victimized peer because they have positive peer regard from those who donot like each other. In fact, these individuals might feel a heightened responsibility to intervene due to their unique position of being intermediaries between peers who do not like each other.

Girls, in comparison to boys, report defending to a higher degree according to self- and teacher reports, observations, and descriptions of one's own behavior in hypothetical situations (Meter \& Card, 2015). We explored whether gender moderated the association between betweenness centrality and defending, with the expectation that the relation may be stronger for girls.

\section{Method}

\section{Participants}

Participants were 485 (55\% girls) adolescents from the $6^{\text {th }}-8^{\text {th }}$ grades in a Southwestern middle school. Their mean age was 13.2 years (range $=11-16$ years). Participants were approximately 44\% White, 21\% Latino/Hispanic, 14\% bi/multi-racial/ethnic, $6 \%$ African American, and $15 \%$ other ethnicities.

Within the school, participants were divided already-established academic teams within their grade. A participant's team included the peers with whom the participants had maximal contact. Peer nomination questionnaires included the names of all students within the team. A non-participating adolescent could still be nominated by peers who did participate, although their data was not usedbecause the network component of the analyses required all nominators to also be nominees.For this reason and/or due to missing all data on one of the other scales, $31 \%$ of participants for whom we had some data were not included in the study. 


\section{Measures and Procedure}

Defending. The proportion of nominations received for six defending items were averaged $(\alpha=.82)$. Students reported who tries to stop situations of peer victimization.The victimization situations are described below.

Betweenness centrality. Participants make unlimited choices of peers fitting the prompt "I like ." Normalized betweenness centrality values were calculated in the six teams within the school using UCInet 6 for Windows (Borgatti, Everett, \& Freeman, 2002) (see Wasserman \& Faust (1994) for calculation of betweenness centrality). Prior to transformation, betweenness centrality scores ranged from 0 to 15.53 . A betweenness centrality value was calculated for each case; scores were used as a continuous predictor. The larger the value, the more a particular participant was on the path between two participants in their network who did not nominate that they liked each other.

Control variables. Perceived popularity, being liked by peers, and victimization were included to control for the effects of these known predictors of defending. Participants reported on a scale from 1 (strongly disagree) to 5 (strongly agree), how much they agreed with the statements "I am popular" and "I am liked by others." Peer-nominated victimization consisted of 6 averaged items $(\alpha=.77)$. The participants nominated which of their peers were pushed around by others, which ones others say mean things to or call names, which peers were hit or kicked by others, which peers others spread rumors about, which peers get ignored or not talked to, and which peers are kept from being part of activities or groups.

A constant of 1 was added to all normalized values of betweenness centrality and a $\log 10$ transformation was applied which resulted in a more normal distribution. The same transformation was applied to the skewed victimization predictor. A hierarchical regression 
analysis was used to test the association between participants' betweennness centrality and defending.

\section{Results}

$M C M C$ imputation was used to estimate the minimal missing data $(0-8.5 \%$, with most variables having no missing data) (Schlomer, Bauman, \& Card, 2010). Means, standard deviations, and correlations between study variables are presented in Table 1. Twenty-two percent of the sample's normalized betweenness centrality scores were 0 . This suggests that a many in the sample do not serve as intermediaries between peers.

The results of the hierarchical regression analysis confirmed the study hypothesis. After controlling for perception of popularity, being liked by others, and own victimization, betweenness centrality was a positive, significant predictor of defending $(\beta=.23, p<.01)$. See Table 2 for complete results. Girls scored significantly higher than boys on defending $(t=3.03, d$ $=.28)$ and betweenness centrality $(t=3.29, d=.30, p \mathrm{~s}<.01)$. Gender moderation was explored, but the interaction of gender and betweenness centrality did not significantly predict defending $(\beta$ $=.05, n s)$.

\section{Discussion}

This study used betweenness centrality based on dyadic nominations of liking to uncover which participants serve as connectors in their peer group. The hypothesis, that betweenness centrality would be associated defending was confirmed.After controlling for other correlates of defending, betweenness centrality was found to be a significant predictor of defending.

Perception of popularity and being likedby otherssignificantly predicted defending. This may be due to a sense of power and ability higher status individuals have to defend victimized 
peers(Pöyhönen et al., 2010). Participants’ own victimization predicted defending. Individuals who understand the plight of their victimized peers may be more apt to defend on their behalf.

This study contributed to research on factors that predict defending of victimized adolescents. Its use of betweenness centrality provided a peer-network level indicator that could be used in conjunction with previously studied interpersonal and individual variables to predict a behavior of interest.

Despite the strength of using network data, because the participants were allowed to nominate individuals who may not have participated, some data were removed to create a square matrix for analysis. This missing information could have affected betweenness centrality, and the non-network data that was removed could have been valuable to the findings. It was necessary to assume that the results of those who provided network data is representative of the larger school population.

The items used to assess victimization did not come from previously-established scales, however had satisfactory reliability. Victimization was associated with other variables in theoretically expected directions. The use of standardized scales could have strengthened the results.

The findings suggest that betweenness centrality isa way to measure potential intermediaries within a crowd whomay feel responsible for intervening and defending their peers. Understanding who is in the best position to defend victimized peers could help those concerned with the wellbeing of adolescents to target the individualswith the ability to serve this intermediary role due to the positive regard they receive from youth who do not like one another. 


\section{References}

Barchia, K., \&Bussey, K. (2011). Predictors of student defenders of peer aggression victims: Empathy and social cognitive factors. International Journal of Behavioral Development, 35(4), 289-297. doi: 10.1177/0165025410396746

Borgatti, S. P. (2005). Centrality and network flow. Social Networks. 27(1), 55-71. doi: 10.1016/j.socnet.2004.11.008

Borgatti, S.P., Everett, M.G. and Freeman, L.C. (2002). Ucinet for Windows: Software for Social Network Analysis. Harvard, MA: Analytic Technologies.

Caravita, S. C. S., Di Blasio, P., \&Salmivalli, C. (2010). Early Adolescents' Participation in Bullying: Is ToM Involved? The Journal of Early Adolescence, 30(1), 138-170. doi: $10.1177 / 0272431609342983$

Card, N. A., Isaacs, J., \& Hodges, E. V. E. (2007). Correlates of school victimization: Implications for prevention and intervention. In J. E. Zins, M. J. Elias \& C. A. Maher (Eds.), Bullying, victimization, and peer harassment: A handbook of prevention and intervention (pp. 339-366). New York: Haworth Press.

Card, N. A., Stucky, B. D., Sawalani, G. M., \& Little, T. D. (2008). Direct and indirect aggression during childhood and adolescence: A meta-analytic review of gender differences, intercorrelations, and relations to maladjustment. Child Development, 79(5), 1185-1229. doi: 10.1111/j.1467-8624.2008.01184.x

Gini, G., Albiero, P., Benelli, B., \&Altoè, G. (2008). Determinants of adolescents' active defending and passive bystanding behavior in bullying. Journal of Adolescence, 31(1), 93-105. doi:10.1016/j.adolescence.2007.05.002 
Hawkins, D. L., Pepler, D. J., \& Craig, W. M. (2001). Naturalistic observations of peer interventions in bullying. Social Development, 10(4), 512-527. doi:

$10.1111 / 1467-9507.00178$

Huitsing, G., Snijders, T. A., Van Duijn, M. A., \&Veenstra, R. (2014). Victims, bullies, and their defenders: A longitudinal study of the coevolution of positive and negative networks. Development and Psychopathology, 1-15. doi: 10.1017/S0954579414000297

Huitsing, G., van Duijn, M. A., Snijders, T. A., Wang, P., Sainio, M., Salmivalli, C., \&Veenstra, R. (2012). Univariate and multivariate models of positive and negative networks: Liking, disliking, and bully-victim relationships. Social Networks, 34(4), 645-657. doi: 10.1016/j.socnet.2012.08.001

Huitsing, G., \&Veenstra, R. (2012). Bullying in classrooms: participant roles from a social network perspective. Aggressive Behavior, 38(6), 494-509. doi: 10.1002/ab.21438

Meter, D. J., \& Card, N. A. (2015). Victims of peer aggression and their defenders: Interdependence theory and an exploration of individual, interpersonal, and contextual effects on the defender participant role. Developmental Review, 38, 222-240. doi:10.1016/j.dr.2015.08.001

Neal, J.W. (2008). Examining relations in childhood relational aggression: The role of peer social networks. (Doctoral dissertation) Retrieved from http://books.google.com/books?id=6fPWV6L2VpUC\&printsec $=$ frontcover $\# \mathrm{v}=$ onepage $\&$ $\mathrm{q} \& \mathrm{f}=$ false.

Pellegrini, A. D., \& Long, J. D. (2002). A longitudinal study of bullying, dominance, and victimization during the transition from primary school through secondary school. British journal of developmental psychology, 20(2), 259-280. 
Pöyhönen, V., Juvonen, J., \&Salmivalli, C. (2010). What does it take to stand up for the victim of bullying? The interplay between personal and social factors. Merrill-Palmer Quarterly, 56(2), 143-163. doi: 10.1353/mpq.0.0046

Pronk, J., Goossens, F. A., Olthof, T., Mey, L. De, \&Willemen, A. M. (2013). Children's intervention strategies in situations of victimization by bullying : Social cognitions of outsiders versus defenders. Journal of School Psychology, 51(6), 669-682. doi:10.1016/j.jsp.2013.09.002

Sainio, M., Veenstra, R., Huitsing, G., \&Salmivalli, C. (2011). Victims and their defenders: A dyadic approach. International Journal of Behavioral Development, 35(2), 144-151. doi: $10.1177 / 0165025410378068$

Salmivalli, C. (2010). Aggression and Violent Behavior Bullying and the peer group : A review. Aggression and Violent Behavior, 15(2), 112-120. doi:10.1016/j.avb.2009.08.007

Salmivalli, C., Lagerspetz, K., Björkqvist, K., Österman, K., \&Kaukialnen, A. (1996). Bullying as a group process: Participant roles and their relations to social status within the group. Aggressive Behavior, 22(1), 1-15. doi: 10.1002/(SICI)1098-2337(1996)22:1<1::AID$\mathrm{AB} 1>3.0 . \mathrm{CO} ; 2-\mathrm{T}$

Salmivalli, C., \&Voeten, M. (2004). Connections between attitudes, group norms , and behaviour in bullying situations, 28(3), 246-258. doi:10.1080/01650250344000488 
Schlomer, G. L., Bauman, S., \& Card, N. A. (2010). Best practices for missing data management in counseling psychology. Journal of Counseling Psychology, 57(1), 1-10. doi: $10.1037 / \mathrm{a} 0018082$

Tisak, M. S., \&Tisak, J. (1996). Expectations and judgments regarding bystanders» and victims responses to peer aggression among early adolescents. Journal of Adolescence, 19(4), 383-392. doi:10.1006/jado.1996.0036

Wasserman, S., \& Faust, K. (1994). Social network analysis: Methods and applications (Vol. 8). New York: Cambridge University Press. 
BETWEENNESS CENTRALITY AND DEFENDING

Table 1

Correlations Among Study Variables

\begin{tabular}{r|lrrrrrrr}
\hline \multicolumn{2}{l}{} & 1 & 2 & 3 & 4 & 5 & Mean & SD \\
\hline 1 & Self-Reported Popularity & 1.00 & & & & & 3.06 & 1.11 \\
2 & Self-Reported Being Liked & $.41^{* *}$ & 1.00 & & & & 4.37 & .99 \\
3 & Victimization & $-.14^{* *}$ & $-.25^{* *}$ & 1.00 & & & .01 & .02 \\
4 & Betweenness Centrality & $.16^{* *}$ & $.18^{* *}$ & $-.10^{*}$ & 1.00 & & .23 & .25 \\
5 & Enacted Defending & $.20^{* *}$ & $.18^{* *}$ & .02 & $.26^{* *}$ & 1.00 & .02 & .01 \\
\hline
\end{tabular}

Notes. Self-report items were on a scale from 1 (strongly disagree) to 5 (strongly agree). Peer nomination items were scored by proportion of peer nominations from total number of nominators. Log 10 transformations were applied to victimization and betweenness centrality variables to reduce skew. $\mathrm{N}=485 .{ }^{*} p<.05 ; * * p<.01$. 
Table 2

Hierarchical Regression Analysis Predicting Enacted Defending

\begin{tabular}{lccc}
\hline Predictors & Adj. $\mathrm{R}^{2}$ & $\mathrm{~B}$ & $\beta$ \\
\hline Step 1 & $.05^{* *}$ & & \\
$\quad$ & & .002 & $.15^{* *}$ \\
Self-Reported Popularity & & .002 & $.14^{* *}$ \\
Self-Reported Being Liked & & .147 & .08 \\
Peer Nominated Victimization & $.10^{* *}$ & & \\
Step 2 & & .002 & $.13^{* *}$ \\
Self-Reported Popularity & & .002 & $.12^{*}$ \\
Self-Reported Being Liked & & .174 & $.09 *$ \\
Peer Nominated Victimization & & .013 & $.23 * *$ \\
Betweenness Centrality & & &. \\
\hline
\end{tabular}

Notes. Log 10 transformations were applied to victimization and betweenness centrality variables to reduce skew. $* p<.05 ; * * p<.01$. 